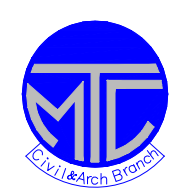

ICCAE

Military Technical College

Kobry Elkobbah,

Cairo, Egypt

\author{
7 th International Conference \\ On Civil \& Architecture \\ Engineering
}

\title{
ANALYSIS of ARCHED COMPOSITE BEAM
}

\author{
Ali.G. Abd El zaher ${ }^{(1)} \quad$ Prof. Dr Mohamed H. El Gamal ${ }^{(2)} \quad$ Dr. Nabil H. Amer ${ }^{(3)}$
}

\begin{abstract}
The present work is established to determine the analysis of the arched composite beam and the studied parameters compared with the straight one. A computer simulation program, using SAP package, was used to predict the elastic state performance for both arched composite beam and straight composite beam. The parameters studied in the analysis using finite element model of the arched composite beam are different spans $(30 \mathrm{~m}, 40 \mathrm{~m}$ and $50 \mathrm{~m})$; different percentages of degrees of curvatures $(0 \%, 2 \%, 4 \%, 6 \%)$ and different spring constant. [3]

The performance of the arched composite beam showed that, when the degree of curvature increased to percentage of $6 \%$, the tensile stress decreases to $70 \%$, the compressive stress decrease to $70 \%$, the deflection decrease to $70 \%$ and the horizontal reaction decrease with $53 \%$ relative to straight beam. Also using springs at end support of stiffness $\mathrm{K}$ (Max-horizontal reaction in case of hinged-hinged support / Max-horizontal displacement in case of hinged-roller support) decrease horizontal reaction $40 \%$ relative to hinged-hinged support.
\end{abstract}

\section{1-Parametric Study}

Two main criteria should be fulfilled, in order to achieve a successful structural analysis. The criteria are the selection of a suitable model to represent the structural system and then perform the analysis of this model with a reasonable degree of accuracy.[2] 
Choosing a suitable model representing the real behavior of the structural system in the most accurate and economical way is the main target of the designer engineer. It is most important to mention that not only the modeling of the structural system that dominates the degree of accuracy of the results, but also some computational errors should be taken into consideration as run-time error and the post-processing of the output results.

The objective of this study is to develop a finite element model representing the cross section of the composite beam, taking into account the fulfillment of the required degree of accuracy in addition of using the most economical representation of the structural system. It should be mentioned that increasing the number of nodes used to represent the model increases the number of degree of freedom in the structural system and thus increases the number of equations to be solved by the computer and naturally the time consumption, which is not convenient from the economical point of view. In this study, several models are tested in order to achieve this goal. Description of the calibration model is chosen as a simply supported single spanning $20 \mathrm{~m}$ with the following properties:

Table [1] Dimensions of Calibration Model

\begin{tabular}{|c|c|c|c|c|c|c|c|c|}
\hline Span & $\begin{array}{c}\text { Thick. of } \\
\text { concrete } \\
\text { slab }\end{array}$ & $\begin{array}{c}\text { Woncrete } \\
\text { slab }\end{array}$ & $\begin{array}{c}\text { Thick. } \\
\text { of top } \\
\text { flange }\end{array}$ & $\begin{array}{c}\text { Width } \\
\text { of top } \\
\text { flange }\end{array}$ & $\begin{array}{c}\text { Thick. } \\
\text { of } \\
\text { bottom } \\
\text { flange }\end{array}$ & $\begin{array}{c}\text { Width of } \\
\text { bottom } \\
\text { flange }\end{array}$ & $\begin{array}{c}\text { Thick. } \\
\text { of the } \\
\text { web }\end{array}$ & $\begin{array}{c}\text { height } \\
\text { of the } \\
\text { web }\end{array}$ \\
\hline $20 \mathrm{~m}$ & $20 \mathrm{~cm}$ & $200 \mathrm{~cm}$ & $2 \mathrm{~cm}$ & $20 \mathrm{~cm}$ & $2 \mathrm{~cm}$ & $30 \mathrm{~cm}$ & $1.7 \mathrm{~cm}$ & $56 \mathrm{~cm}$ \\
\hline
\end{tabular}

\section{Numerical Approaches:}

1-Numerical approach (1), which use four-nodded shell elements in modeling steel and concrete elements.

2-Numerical approach (2), which use eight-nodded solid elements in modeling steel and concrete elements.

The two approaches compared with the first principle design. All the models fulfill the conditions of the Egyptian Code of Practice (E.C.P.)

\section{Elements Types Used in Approach (1)}


(1) Concrete deck is modeled with four-nodded shell element (includes membrane and bending effects).

(2) Girder flanges are modeled with four-nodded shell element (includes membrane and bending effects).

(3) Girder web is modeled with four-nodded shell element (includes membrane and bending effects).

(4) Shear connectors are modeled with axial and bending effects connecting the girder upper flange and the concrete deck over the web node along the beam length representing the shear connectors.

\section{Elements Types Used in Approach (2)}

(1) Concrete deck is modeled with eight-nodded solid element

(2) Girder flanges are modeled eight nodded solid element

(3) Girder web is modeled eight nodded solid element

(4) Shear connectors are modeled with axial and bending effects connecting the girder upper flange and the concrete deck over the web node along the beam length representing the shear connectors.

\section{2-Description of the studied beams}

In this research, a parametric study has been conducted to study the behavior of the simply supported arched composite-girder bridges. The considered parameters are the span length measured along the centerline of the bridge and the degree of curvature. The modulus of elasticity of steel is assumed to be $2.1 \times 10^{6} \mathrm{~kg} / \mathrm{cm}^{2}$ and Poisson's ratio is taken 0.3.The concrete strength is assumed to be $400 \mathrm{~kg} / \mathrm{cm}^{2}$. According to the (E.C.P.) for Steel Constructions and Bridges 2001, the modular ratio " $n$ " is 8 for such concrete strength, so the modulus of elasticity of the concrete is assumed to be $3.7 \times 10^{5} \mathrm{~kg} / \mathrm{cm}^{2}$ and Poisson's ratio is taken 0.2 .

In order to make proper comparison between the effects of parameters to be studied 
on the behavior of the arched composite beams, it is decided to take a constant designed cross section. All arched beams are consisted of steel l-girder. The cross section of the steel girders is taken as built-up-section consists of web plate and two flanges connected to the concrete slab with shear connectors based on the assumption of full interaction. The steel cross -section is chosen different for all of the three models.

Table [2] Models Dimensions.

\begin{tabular}{|c|c|c|c|c|c|c|c|c|}
\hline Span & $\begin{array}{c}\text { Thickness } \\
\text { of } \\
\text { concrete } \\
\text { slab }\end{array}$ & $\begin{array}{c}\text { Width of } \\
\text { the } \\
\text { concrete } \\
\text { slab }\end{array}$ & $\begin{array}{c}\text { Thickness } \\
\text { of top } \\
\text { flange }\end{array}$ & $\begin{array}{c}\text { Width } \\
\text { of the } \\
\text { top } \\
\text { flange }\end{array}$ & $\begin{array}{c}\text { Thickness } \\
\text { of bottom } \\
\text { flange }\end{array}$ & $\begin{array}{c}\text { Width } \\
\text { of the } \\
\text { bottom } \\
\text { flange }\end{array}$ & $\begin{array}{c}\text { Thickness } \\
\text { of the web }\end{array}$ & $\begin{array}{c}\text { Height of } \\
\text { the web }\end{array}$ \\
\hline $30 \mathrm{~m}$ & $25 \mathrm{~cm}$ & $250 \mathrm{~cm}$ & $2 \mathrm{~cm}$ & $20 \mathrm{~cm}$ & $3 \mathrm{~cm}$ & $40 \mathrm{~cm}$ & $1.2 \mathrm{~cm}$ & $110 \mathrm{~cm}$ \\
\hline $40 \mathrm{~m}$ & $25 \mathrm{~cm}$ & $250 \mathrm{~cm}$ & $2 \mathrm{~cm}$ & $24 \mathrm{~cm}$ & $4 \mathrm{~cm}$ & $40 \mathrm{~cm}$ & $1.5 \mathrm{~cm}$ & $140 \mathrm{~cm}$ \\
\hline $50 \mathrm{~m}$ & $25 \mathrm{~cm}$ & $250 \mathrm{~cm}$ & $2 \mathrm{~cm}$ & $30 \mathrm{~cm}$ & $5 \mathrm{~cm}$ & $50 \mathrm{~cm}$ & $1.8 \mathrm{~cm}$ & $173 \mathrm{~cm}$ \\
\hline
\end{tabular}

All the parameters have been tested in case of full loading of live load equal to 700 $\mathrm{kg} / \mathrm{m}^{2}$. The degree of curvature is taken as: $0 \%$ (straight), $2 \%, 4 \%$ and $6 \%$, and the span length $30 \mathrm{~m}, 40 \mathrm{~m}$ and $50 \mathrm{~m}$.

The horizontal distance between the two end supports is defined as the span of the arch $(L)$ and the height of the Crown Point above the line joining the supports are called as the rise of the $\operatorname{arch}(\mathrm{h})$. The degree of curvature $(\mathrm{H})$ can be found by subdividing of the elevation at the mid span over the whole span. Consequently it is more convenient to provide springs with stiffness $\mathrm{K}$ at the supports to reduce the horizontal forces. The spring constant $(\mathrm{K})$ can be found by subdividing the maximum horizontal force (ton) in the hinged-hinged model by the horizontal displacement $(\mathrm{m})$ in the hinged-roller model.

The studied parameters are max. tensile stress, max. compressive stress, horizontal reaction at the support, max. spring displacement and the deflection at the middle span (Figure 1). 


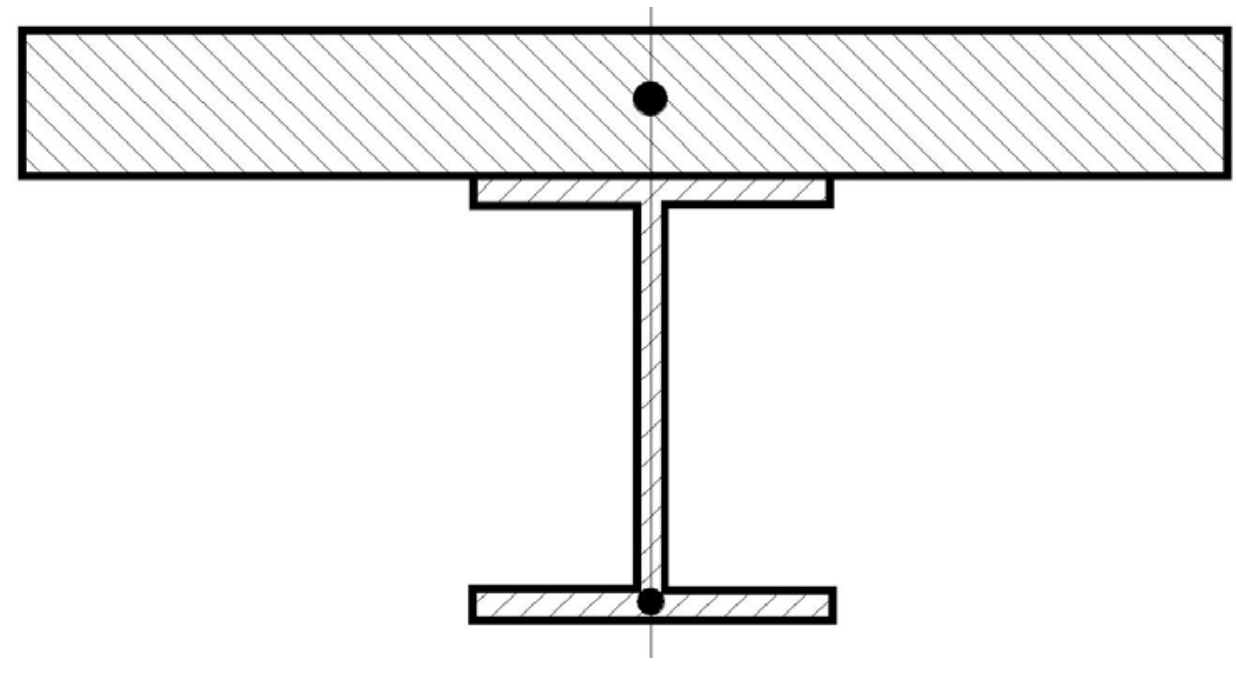

A

Fig (1-a) Maximum tensile stress at the lower flange.

Maximum compressive stress at the concrete slab.

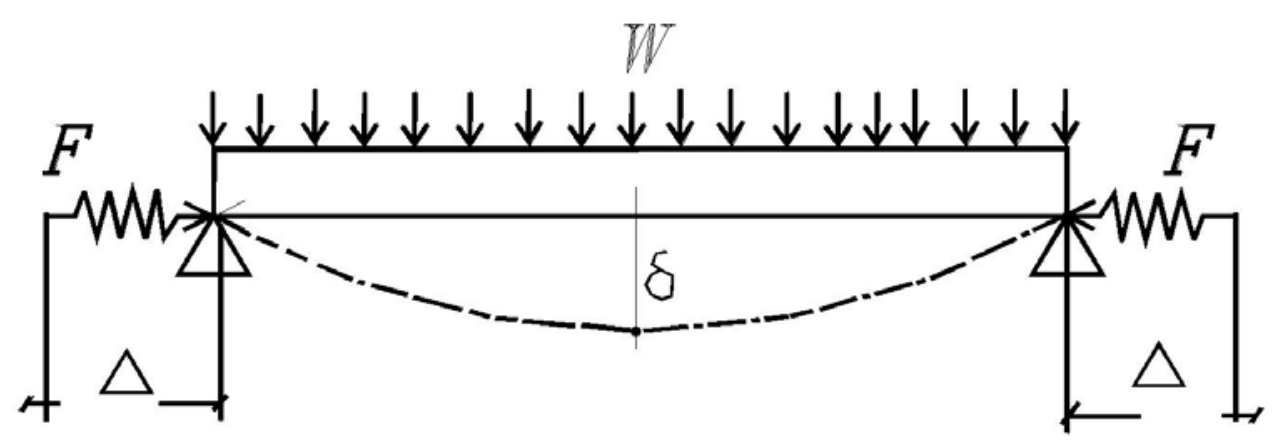

Fig (1-b) (F) horizontal reaction at the support (ton)

$(\Delta)$ spring displacement $(\mathrm{cm})$

(ठ) Deflection in the middle span $(\mathrm{cm})$

\section{3-Results and discussion}

\section{A- Results of the calibration model}


Table [3]: Results of approach (1) compared to analytical solution.

\begin{tabular}{|c|c|c|c|}
\hline Parameters & Analytical & Approach (1) & Deviation \\
\hline Deflection & $6.13 \mathrm{~cm}$ & $6.86 \mathrm{~cm}$ & $11.9 \%$ \\
\hline $\mathbf{F}_{\text {top }}$ concrete & $-105.03 \mathrm{~kg} / \mathrm{cm}^{2}$ & $-107.6 \mathrm{~kg} / \mathrm{cm}^{2}$ & $2 \%$ \\
\hline $\mathbf{F}_{\text {bottom }}$ steel & $1876.18 \mathrm{~kg} / \mathrm{cm}^{2}$ & $1819.5 \mathrm{~kg} / \mathrm{cm}^{2}$ & $3 \%$ \\
\hline Reaction & 25 ton & $25.53 \mathrm{ton}$ & $0.02 \%$ \\
\hline
\end{tabular}

$\mathrm{F}_{\text {top }}$ concrete: Total axial stress in the concrete deck.

$F_{\text {bottom }}$ steel: Total axial stress in the girder lower flange.

Deviation: (Approach1 - Analytical) / Analytical

Table [4]: Results of approach (2) compared to analytical solution.

\begin{tabular}{|c|c|c|c|}
\hline Parameters & Analytical & Approach2 & Deviation \\
\hline Deflection & $6.13 \mathrm{~cm}$ & $6.27 \mathrm{~cm}$ & $2 \%$ \\
\hline $\mathbf{F}_{\text {top }}$ & $-105.03 \mathrm{~kg} / \mathrm{cm}^{2}$ & $-104.7 \mathrm{~kg} / \mathrm{cm}^{2}$ & $0.3 \%$ \\
\hline $\mathbf{F}_{\text {bottom }}$ & $1876.18 \mathrm{~kg} / \mathrm{cm}^{2}$ & $1880.7 \mathrm{~kg} / \mathrm{cm}^{2}$ & $0.24 \%$ \\
\hline Reaction & 25 ton & $25.7 \mathrm{ton}$ & $0.66 \%$ \\
\hline
\end{tabular}

$F_{\text {top }}$ concrete: Total axial force in the concrete deck and the girder upper flange.

$F_{\text {bottom }}$ steel: Total axial force in the girder lower flange.

Deviation: (Approach1 - Analytical) / Analytical

Table [5] Results of approach (1) compared to Results of approach (2)

\begin{tabular}{|c|c|c|c|c|}
\hline Parameters & Analytical & Approach1 & Approach2 & Deviation \\
\hline Deflection & $6.13 \mathrm{~cm}$ & $6.86 \mathrm{~cm}$ & $6.27 \mathrm{~cm}$ & $3 \%$ \\
\hline
\end{tabular}




\begin{tabular}{|c|c|c|c|c|}
\hline $\boldsymbol{F}_{\text {top }}$ & $-105.03 \mathrm{~kg} / \mathrm{cm}^{2}$ & $-107.6 \mathrm{~kg} / \mathrm{cm}^{2}$ & $-104.7 \mathrm{~kg} / \mathrm{cm}^{2}$ & $3.2 \%$ \\
\hline $\boldsymbol{F}_{\text {bott. }}$ & $1876.18 \mathrm{~kg} / \mathrm{cm}^{2}$ & $1819.5 \mathrm{~kg} / \mathrm{cm}^{2}$ & $1880.7 \mathrm{~kg} / \mathrm{cm}^{2}$ & $8 \%$ \\
\hline Reaction & 25.53 ton & 25.53 ton & 25.7 ton & $0.1 \%$ \\
\hline
\end{tabular}

Deviation: (Approach1 - Approach2) /Approach1

To ensure the reliability of this model; the accuracy of the results compared to the analytical solution. The results of approach (2) are more accurate but approach (2) consumes significant time than approach (1). The deviations between approach(1) and approach (2) are too small so, we can conclude that Approach(1) composed of shell elements including membrane and bending effects representing the model, is considered a reliable finite element model for the study of the arched composite I-girder bridges using the SAP2000.

\section{B- Results of the Current Research}

\section{1-The Tensile Stresses at Bottom Flange}

\section{1-1Span=30m}

Figure [2] and Table [6] represent the change in tensile stresses at the bottom flange with degree of curvature $(\mathrm{H})$ and the spring constant $(\mathrm{K})$ for different values of span length $(\mathrm{L})$ and considering four different degrees of curvatures. Generally, the tensile stress at the lower flange decreases with the increase in the degree of curvature. For hinged-hinged support, the reduction ranges between $45 \%$ to $76 \%$ as the degree of curvature increases from $2 \%$ to $6 \%$. Also, the tensile stresses are studied for different spring constants. The results showed that the general behavior is a decrease in tensile stress with the increase of spring constant and it can be explained as follows:

- For spring constant $=\mathrm{K}$, the tensile stress at the lower flange decreases with the increase in the degree of curvature. The reduction ranges between $15 \%$ to $25 \%$ as the degree of curvature increases from $2 \%$ to $6 \%$.

- For hinged-roller support, the degree of curvature has no effect on max- tensile stress.

\section{1-2 Span $=40 \mathrm{~m}$}


Figure [3] and Table [7] represent the change in tensile stresses at the bottom flange with degree of curvature $(\mathrm{H})$ and the spring constant $(\mathrm{K})$ for different values of span length $(\mathrm{L})$ and considering four different radius of curvatures.

Generally, the tensile stress at the lower flange decreases with the increase in the degree of curvature. For hinged-hinged support the decrease ranges between $49 \%$ to $80 \%$ as the degree of curvature increase from $2 \%$ to $6 \%$.

- For spring constant $=\mathrm{K}$ the tensile stress at the lower flange decreases with the increase in the degree of curvature. The decrease ranges between $16 \%$ to $27 \%$ as the degree of curvature increases from $2 \%$ to $6 \%$.

- For hinged-roller support the degree of curvature has no effect on max- tensile stress.

\section{1-3 $\mathrm{Span}=50 \mathrm{~m}$}

Figure [4] and Table [8] represents the change in stresses at the bottom flange with degree of curvature $(\mathrm{H})$ and the spring constant $(\mathrm{K})$ for different values of span length $(\mathrm{L})$ and considering four different degree of curvatures.

Generally, the tensile stress at the lower flange decreases with the increase in the degree of curvature. For hinged-hinged support the decrease ranges between $55 \%$ to $86 \%$ as the degree of curvature increase from $2 \%$ to $6 \%$.

- For spring constant= $\mathrm{K}$ the tensile stress at the lower flange decreases with the increase in the degree of curvature. The decrease ranges between $18 \%$ to $29 \%$ as the degree of curvature increases from $2 \%$ to $6 \%$.

- For hinged-roller support the degree of curvature has no effect on max- tensile stress.

\section{2-The compressive stresses in concrete flange}

\section{2-1 Span $=30 \mathrm{~m}$}

Figure [5] and Table [9] represent the change in compressive stresses in the concrete flange with degree of curvature $(H)$ for different values of span length $(L)$ and considering four different degrees of curvature.

Generally, the compressive stress in the concrete flange decreases with the increase in 
the degree of curvature. For hinged-hinged support the decrease ranges between $30 \%$ to $59 \%$ as the degree of curvature increases from $2 \%$ to $6 \%$. Also the compressive stresses are studied for different spring constants. The results showed that the general behavior is a decrease in compressive stress with the increase of end bearings and it can be discussed as follows:

- For spring constant $=\mathrm{K}$ the compressive stress in the concrete flange decreases with the increase in the degree of curvature. The decrease ranges between $15 \%$ to $29 \%$ as the degree of curvature increases from $2 \%$ to $6 \%$.

- For hinged-roller support the degree of curvature has no effect on max- tensile stress.

\section{2-2 $\operatorname{Span}=40 \mathrm{~m}$}

Figure [6] and Table [10] represent the change in compressive stresses at the concrete flange with degree of curvature $(\mathrm{H})$ and the spring constant $(\mathrm{K})$ for different values of span length $(L)$ and considering four different degree of curvatures.

Generally, the compressive stress at the concrete flange decreases with the increase in the degree of curvature. For hinged-hinged support the decrease ranges between $32 \%$ to $61 \%$ as the degree of curvature increases from $2 \%$ to $6 \%$. Also the compressive stress is studied for different spring constants. The results showed that the general behavior is a decrease in compressive stress with the increase of spring constant and it can be discussed as follows:

- For spring constant $=\mathrm{K}$ the compressive stress in the concrete flange decreases with the increase in the degree of curvature. The decrease ranges between $17 \%$ to $31 \%$ as the degree of curvature increases from $2 \%$ to $6 \%$.

- For hinged-roller support the degree of curvature has no effect on max-compressive stress.

\section{2-3 Span=50m}

Figure [7] and Table [11] represent the change in compressive stresses in the concrete flange with degree of curvature $(\mathrm{H})$ and the spring constant $(\mathrm{K})$ for different values of span length $(L)$ and considering four different degree of curvatures.

Generally, for span $=50 \mathrm{~m}$ the compressive stress in the lower flange decreases with the increase in the degree of curvature. For hinged-hinged support the decrease ranges 
between $33 \%$ to $63 \%$ as the degree of curvature increases from $2 \%$ to $6 \%$. Also the compressive stress is studied for different spring constants. The results showed that the general behavior is a decrease in compressive stress with the increase of spring constant and it can be discussed as follows:

- For spring constant $=\mathrm{K}$ the compressive stress in the concrete flange decreases with the increase in the degree of curvature. The decrease ranges between $18 \%$ to $33 \%$ as the degree of curvature increases from $2 \%$ to $6 \%$.

- For hinged-roller support the degree of curvature has no effect on max-compressive stress.

\section{3- The horizontal reaction}

\section{3-1 Span $=30 \mathrm{~m}$}

Figure [8] and Table [12] represent the change in horizontal reaction at the support with degree of curvature $(\mathrm{H})$ and the spring constant $(\mathrm{K})$ for different values of span length $(\mathrm{L})$ and considering four different degree of curvatures. Generally, the horizontal reaction at the support decreases with the increase in the degree of curvature. For hinged-hinged support the decrease ranges between $18 \%$ to $45 \%$ as the degree of curvature increases from $2 \%$ to $6 \%$. Also the horizontal reaction is studied for different spring constants. The results showed that the general behavior is an increase in horizontal reaction with the increase of spring constant and it can be discussed as follows:

- For spring constant $=\mathrm{K}$ the horizontal reaction at the support decreases with the increase in the degree of curvature. The decrease ranges between $18 \%$ to $45 \%$ as the degree of curvature increases from $2 \%$ to $6 \%$.

- For hinged-roller support the degree of curvature has no effect on max- horizontal reaction stress.

\section{3-2 Span $=40 \mathrm{~m}$}

Figure [9] and Table [13] represent the change in horizontal reaction at the support with degree of curvature $(\mathrm{H})$ and the spring constant $(\mathrm{K})$ for different values of span length $(\mathrm{L})$ and considering four different degree of curvatures. 
Generally, the horizontal reaction at the support decreases with the increase in the degree of curvature. For hinged-hinged support the decrease ranges between $19 \%$ to $47 \%$ as the degree of curvature increase from $2 \%$ to $6 \%$. Also the horizontal reaction is studied for different spring constants. The results showed that the general behavior is an increase in horizontal reaction with the increase of spring constant and it can be discussed as follows:

- For spring constant $=\mathrm{K}$ the horizontal reaction at the support decreases with the increase in the degree of curvature. The decrease ranges between $19 \%$ to $47 \%$ as the degree of curvature increases from $2 \%$ to $6 \%$.

- For hinged-roller support the horizontal reaction at the support equal to Zero.

\section{3-3 Span $=50 \mathrm{~m}$}

Figure [10] and Table [14] represent the change in horizontal reaction at the support with degree of curvature $(\mathrm{H})$ and the spring constant $(\mathrm{K})$ for different values of span length $(\mathrm{L})$ and considering four different degree of curvatures.

Generally, the horizontal reaction at the support decreases with the increase in the degree of curvature. For hinged-hinged support the decrease ranges between $18 \%$ to $48 \%$ as the degree of curvature increases from $2 \%$ to $6 \%$. Also the horizontal reaction is studied for different spring constants. The results showed that the general behavior is an increase in horizontal reaction with the increase of spring constant and it can be discussed as follows:

- For spring constant $=\mathrm{K}$ the horizontal reaction at the support decreases with the increase in the degree of curvature. The decrease ranges between $18 \%$ to $47 \%$ as the degree of curvature increases from $2 \%$ to $6 \%$.

- For hinged-roller support the horizontal reaction at the support equal to Zero.

\section{4- The displacement at support}

\section{4-1 Span $=30 \mathrm{~m}$}

Figure [11] and Table [15] represent the change in displacement in the spring at support with degree of curvature $(\mathrm{H})$ and the spring constant $(\mathrm{K})$ for different values of span length $(L)$ and considering four different degree of curvatures. 
Generally, the displacement increases with the increase in the degree of curvature. For hinged-hinged support the displacement was equal Zero. Also the displacement is studied for different spring constants. The results showed that the general behavior is an increase in displacement with the decrease of spring constant and it can be discussed as follows:

- For spring constant $=\mathrm{K}$ the displacement increases with the increase in the degree of curvature. The increase ranges between $49 \%$ to $153 \%$ as the degree of curvature increases from $2 \%$ to $6 \%$.

- For hinged-roller support displacement increases with the increases in the degree of curvature, the increase ranges between $50 \%$ to $158 \%$ as the degree of curvature increases from $2 \%$ to $6 \%$.

\section{4-2 Span $=40 \mathrm{~m}$}

Figure [12] and Table [16] represent the change in displacement in the spring at support with degree of curvature $(H)$ and the spring constant $(K)$ for different values of span length $(L)$ and considering four different radius of curvatures.

Generally, the displacement increases with the increase in the degree of curvature. For hinged-hinged support the displacement was equal Zero. Also the displacement is studied for different spring constants. The results showed that the general behavior is an increase in displacement with the decrease of spring constant and it can be discussed as follows:

- For spring constant $=\mathrm{K}$ the displacement increases with the increase in the degree of curvature. The decrease ranges between $55 \%$ to $172 \%$ as the degree of curvature increases from $2 \%$ to $6 \%$.

- For hinged-roller support displacement increases with the increase in the degree of curvature the increase ranges between $55 \%$ to $173 \%$ as the degree of curvature increases from $2 \%$ to $6 \%$.

\section{4-3 $\mathrm{Span}=50 \mathrm{~m}$}

Figure [13] and Table [17] represent the change in displacement in the spring at support with degree of curvature $(H)$ and the spring constant $(K)$ for different values of span length $(L)$ and considering four different degree of curvatures.

Generally, the displacement increases with the increase in the degree of curvature. For hinged-hinged support the displacement was equal Zero. Also the displacement is studied 
for different spring constants. The results showed that the general behavior is an increase in displacement with the decrease of spring constant and it can be discussed as follows:

- For spring constant $=\mathrm{K}$ the displacement increases with the increase in the degree of curvature. The increase ranges between $61 \%$ to $192 \%$ as the degree of curvature increases from $2 \%$ to $6 \%$.

- For hinged-roller support displacement increases with the increase in the degree of curvature. The increase ranges between $62 \%$ to $195 \%$ as the degree of curvature increases from $2 \%$ to $6 \%$.

\section{5-The deflection at mid-span}

\section{5-1 Span $=30 \mathrm{~m}$}

Figure [14] and Table [18] represent the change in deflection at mid-span with degree of curvature $(H)$ and the spring constant $(K)$ for different values of span length $(L)$ and considering four different degree of curvatures.

Generally, for span $=30 \mathrm{~m}$ the deflection at mid-span decreases with the increase in the degree of curvature. For hinged-hinged support the decrease ranges between $42 \%$ to $73 \%$ as the degree of curvature increases from $2 \%$ to $6 \%$. Also the deflection is studied for different spring constants. The results showed that the general behavior is a decrease in deflection with the increase of spring constant and it can be discussed as follows:

- For spring constant $=\mathrm{K}$ the deflection at mid-span decreases with the increase in the degree of curvature. The decrease ranges between $15 \%$ to $27 \%$ as the degree of curvature increases from $2 \%$ to $6 \%$.

- For hinged-roller support the degree of curvature has no effect on deflection.

\section{5-2 Span $=40 \mathrm{~m}$}

Figure [15] and Table [19] represent the change in deflection at mid-span with degree of curvature $(H)$ and the spring constant $(K)$ for different values of span length $(L)$ and considering four different degree of curvatures.

Generally, the deflection at mid-span decreases with the increase in the degree of curvature. For hinged-hinged support the decrease ranges between $45 \%$ to $76 \%$ as the degree of curvature increases from $2 \%$ to $6 \%$. Also, the deflection is studied for different 
spring constants. The results showed that the general behavior is a decrease in deflection with the increase of spring constant and it can be discussed as follows:

- For spring constant $=\mathrm{K}$ the deflection at mid-span decreases with the increase in the degree of curvature. The decrease ranges between $17 \%$ to $28 \%$ as the degree of curvature increases from $2 \%$ to $6 \%$.

- For hinged-roller support the degree of curvature has no effect on deflection.

\section{5-3 Span $=50 \mathrm{~m}$}

Figure [16] and Table [20] represent the change in deflection at mid-span with degree of curvature $(\mathrm{H})$ and the spring constant $(\mathrm{K})$ for different values of span length $(\mathrm{L})$ and considering four different degree of curvatures.

Generally, the deflection at mid-span decreases with the increase in the degree of curvature. For hinged-hinged support the decrease ranges between $47 \%$ to $78 \%$ as the degree of curvature increases from $2 \%$ to $6 \%$. Also the deflection is studied for different spring constants. The results showed that the general behavior is a decrease in deflection with the increase of spring constant and it can be discussed as follows:

- For spring constant $=\mathrm{K}$ the deflection at mid-span decreases with the increase in the degree of curvature. The decrease ranges between $18 \%$ to $30 \%$ as the degree of curvature increases from $2 \%$ to $6 \%$.

- For hinged-roller support the degree of curvature has no effect on deflection. 


\begin{tabular}{|c|c|c|c|}
\hline TYPE & $\infty \mathrm{K}$ & $\mathrm{K}$ & $0 \mathrm{~K}$ \\
\hline STRAIGHT & 655.9 & 1170.5 & 1936 \\
\hline $\mathrm{H}=2 \%$ & 359.8 & 993.7 & 1940.4 \\
\hline $\mathrm{H}=4 \%$ & 223.4 & 914.2 & 1946.4 \\
\hline $\mathrm{H}=6 \%$ & 154.6 & 875.8 & 1954.1 \\
\hline
\end{tabular}

\begin{tabular}{|c|c|c|c|}
\hline TYPE & $\infty \mathrm{K}$ & $\mathrm{K}$ & $0 \mathrm{~K}$ \\
\hline STRAIGHT & 634.9 & 1130.9 & 1871 \\
\hline $\mathrm{H}=2 \%$ & 288.6 & 924.3 & 1874.7 \\
\hline $\mathrm{H}=4 \%$ & 150.6 & 843.7 & 1877.2 \\
\hline $\mathrm{H}=6 \%$ & 89.2 & 809.4 & 1887.4 \\
\hline
\end{tabular}

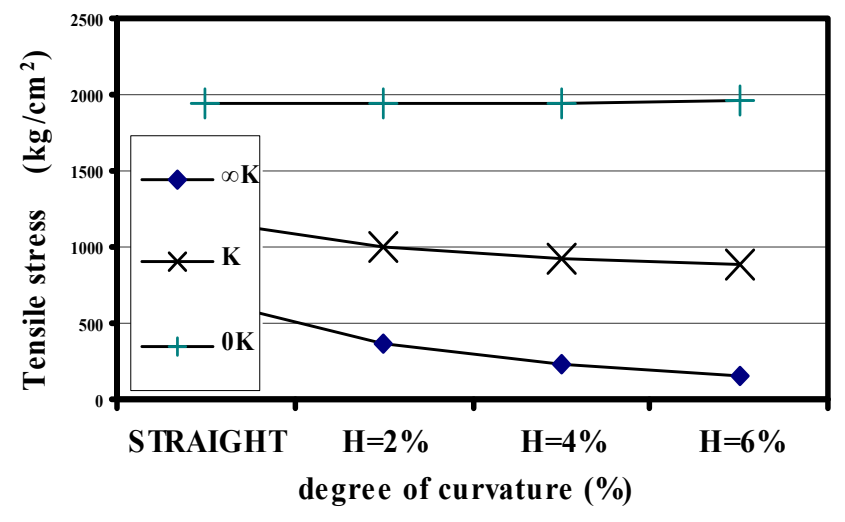

Table [6] Tensile stresses at lower flange.

Fig [2] Max-tensile Stress Vs stress at the. Degree of curvature $(S=30 \mathrm{~m})$.

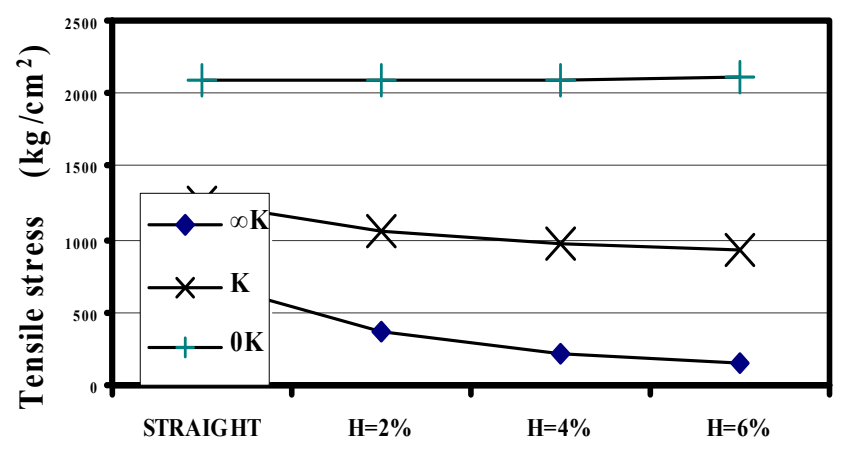

Degree of curvature (\%) 


\begin{tabular}{|c|c|c|c|}
\hline TYPE & $\infty \mathrm{K}$ & $\mathrm{K}$ & $0 \mathrm{~K}$ \\
\hline STRAIGHT & 62.77 & 71.6 & 84.87 \\
\hline $\mathrm{H}=2 \%$ & 43.8 & 60.56 & 85.5 \\
\hline $\mathrm{H}=4 \%$ & 30.12 & 54.2 & 86.4 \\
\hline $\mathrm{H}=6 \%$ & 25.9 & 50.5 & 87.4 \\
\hline
\end{tabular}

Table [7] represent the results of the tensile

Fig [3] Max-tensile Stress vs. Degree stress at the bottom flange of curvature $(S=40 \mathrm{~m})$

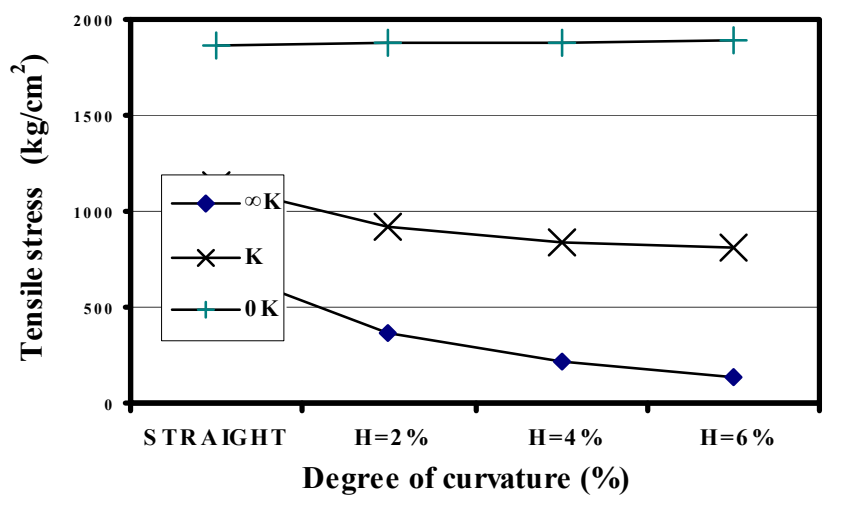

\begin{tabular}{|c|c|c|c|}
\hline TYPE & $\infty \mathrm{K}$ & $\mathrm{K}$ & $0 \mathrm{~K}$ \\
\hline STRAIGHT & 82.7 & 92 & 105.73 \\
\hline $\mathrm{H}=2 \%$ & 56.5 & 76.6 & 106.66 \\
\hline $\mathrm{H}=4 \%$ & 41.5 & 68 & 107.7 \\
\hline $\mathrm{H}=6 \%$ & 32.5 & 63.1 & 108.9 \\
\hline
\end{tabular}

Table [8] represents the results of the tensile

Fig [4] Max-tensile Stress Vs Degree Stress at the bottom flange of curvature $(S=50 \mathrm{~m})$

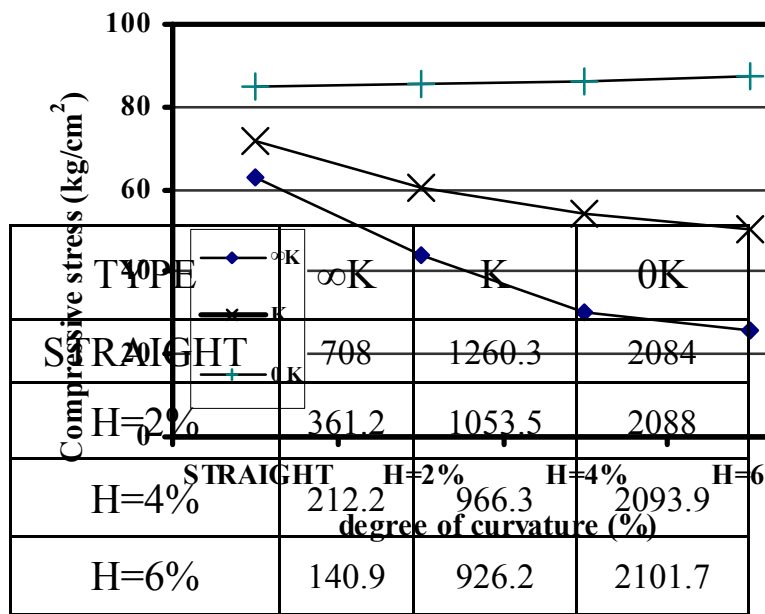

Stress at the Concrete slab.
Table [9] the results of the Compressive Fig [5] Max-Compressive Stress Vs .Degree of curvature $(S=30 \mathrm{~m})$.

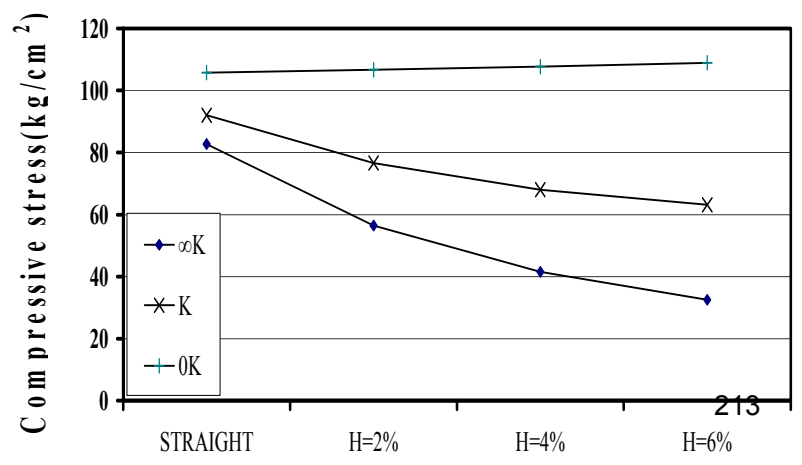

Degree of curvature (\%) 


\begin{tabular}{|c|c|c|c|}
\hline TYPE & $\infty \mathrm{K}$ & $\mathrm{K}$ & $0 \mathrm{~K}$ \\
\hline STRAIGHT & 219.24 & 131.13 & 0 \\
\hline $\mathrm{H}=2 \%$ & 180.26 & 107.97 & 0 \\
\hline $\mathrm{H}=4 \%$ & 146.05 & 87.53 & 0 \\
\hline $\mathrm{H}=6 \%$ & 120.07 & 71.98 & 0 \\
\hline
\end{tabular}

Fig [6] Max- Compressive Stress Stress at the Concrete slab.

Table [10] the results of the Compressive Vs. Degree of curvature $(S=40 \mathrm{~m})$

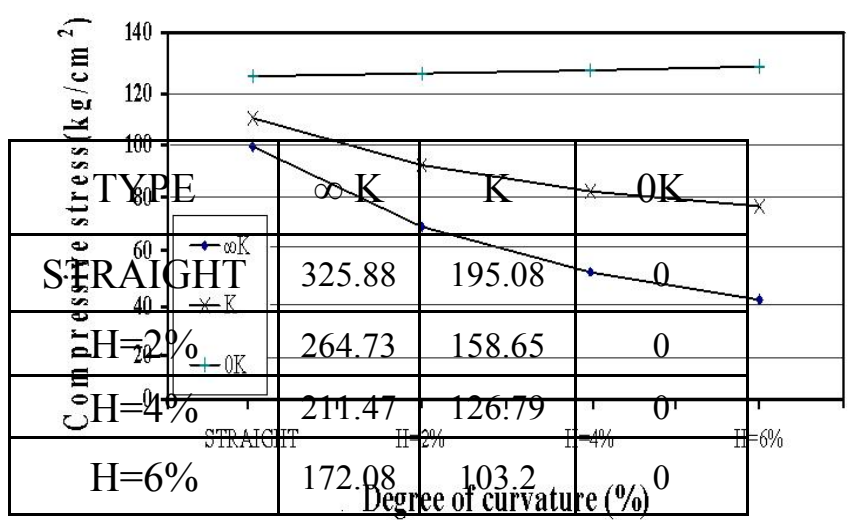

Table [11] the results of the Compressive

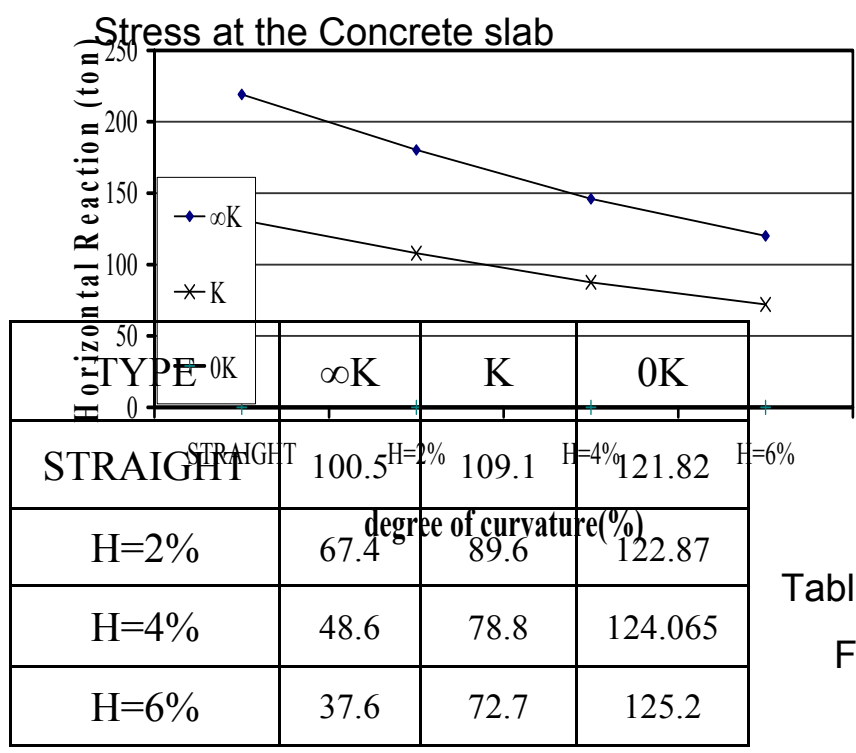

vs. degree of curvature $(S=30 \mathrm{~m})$

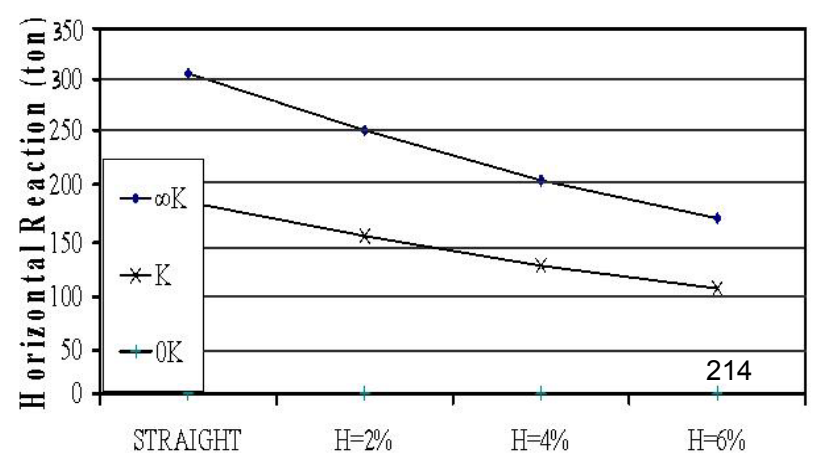

Fig [7] Max- Compressive Stress Vs. Degree of curvature $(S=50 \mathrm{~m})$
Fig [8] Max-horizontal reaction
reaction at support. 


\begin{tabular}{|c|c|c|c|}
\hline TYPE & $\infty \mathrm{K}$ & $\mathrm{K}$ & $0 \mathrm{~K}$ \\
\hline STRAIGHT & 0 & 0.376 & 1.842 \\
\hline $\mathrm{H}=2 \%$ & 0 & 0.56 & 2.767 \\
\hline $\mathrm{H}=4 \%$ & 0 & 0.751 & 3.726 \\
\hline $\mathrm{H}=6 \%$ & 0 & 0.953 & 4.744 \\
\hline
\end{tabular}

Table [13] the results of the horizontal reaction at Support.

\begin{tabular}{|c|c|c|c|}
\hline TYPE & $\infty \mathrm{K}$ & $\mathrm{K}$ & $0 \mathrm{~K}$ \\
\hline STRAIGHT & 0 & 0.537 & 2.664 \\
\hline $\mathrm{H}=2 \%$ & 0 & 0.831 & 4.122 \\
\hline $\mathrm{H}=4 \%$ & 0 & 1.136 & 5.623 \\
\hline $\mathrm{H}=6 \%$ & 0 & 1.46 & 7.277 \\
\hline
\end{tabular}

Table [14] the results of the Horizontal Reaction at support.
Fig [9] Max- horizontal reaction

vs. degree of curvature ( $S=40 \mathrm{~m})$

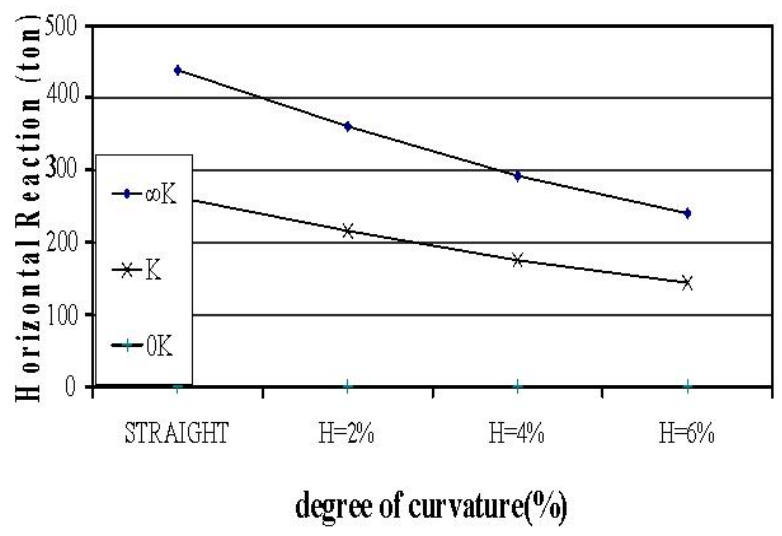

Fig [10] Max- horizontal Reaction Vs Degree of curvature ( $S=50 \mathrm{~m})$

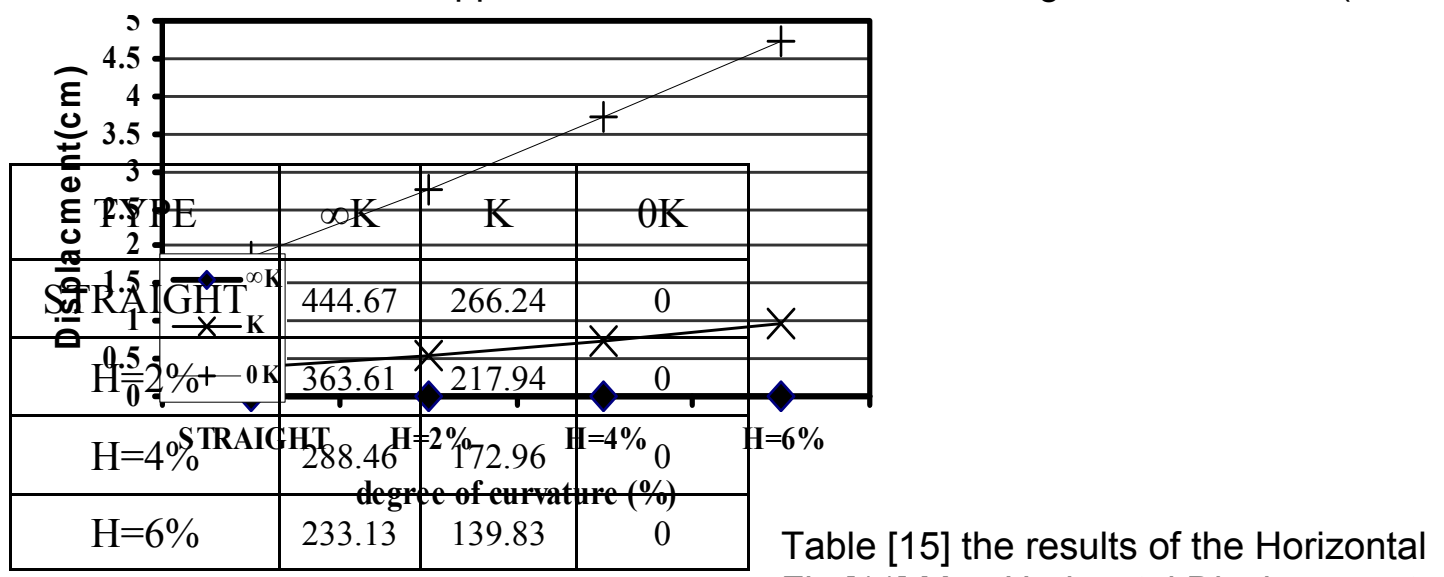

Displacement at support.

Fig [11] Max-Horizontal Displacement Vs .Degree of curvature $(S=30 \mathrm{~m})$

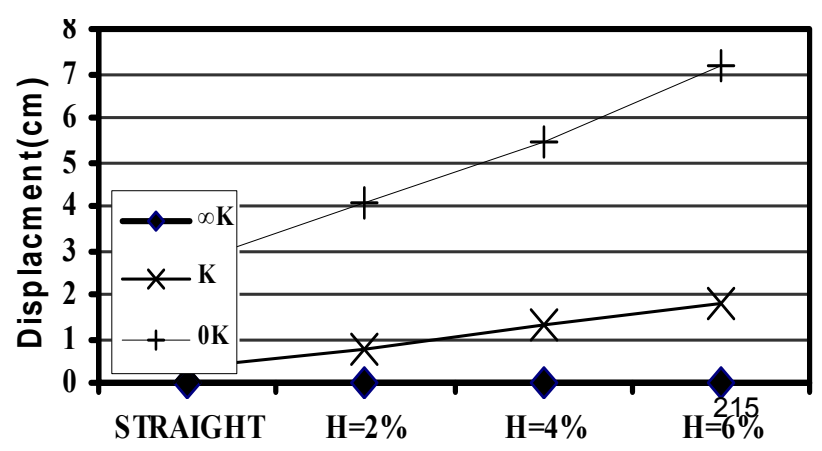

degree of curvature (\%) 


\begin{tabular}{|c|c|c|c|}
\hline TYPE & $\infty \mathrm{K}$ & $\mathrm{K}$ & $0 \mathrm{~K}$ \\
\hline STRAIGHT & 3.406 & 5.66 & 9 \\
\hline $\mathrm{H}=2 \%$ & 1.968 & 4.785 & 8.976 \\
\hline $\mathrm{H}=4 \%$ & 1.28 & 4.358 & 8.965 \\
\hline $\mathrm{H}=6 \%$ & 0.917 & 4.14 & 8.961 \\
\hline
\end{tabular}

Table [16] the results of the Horizontal Displacement at support.

\begin{tabular}{|c|c|c|c|}
\hline TYPE & $\infty \mathrm{K}$ & $\mathrm{K}$ & $0 \mathrm{~K}$ \\
\hline STRAIGHT & 5.628 & 9.141 & 14.375 \\
\hline $\mathrm{H}=2 \%$ & 3.103 & 7.606 & 14.337 \\
\hline $\mathrm{H}=4 \%$ & 1.958 & 6.911 & 14.326 \\
\hline $\mathrm{H}=6 \%$ & 1.374 & 6.564 & 14.339 \\
\hline
\end{tabular}

Table [17] the results of the Horizontal Displacement at support

\begin{tabular}{|c|c|c|c|}
\hline TYPE & $\infty \mathrm{K}$ & $\mathrm{K}$ & $0 \mathrm{~K}$ \\
\hline STRAIGHT & 0 & 0.603 & 2.968 \\
\hline $\mathrm{H}=2 \%$ & 0 & 0.971 & 4.816 \\
\hline $\mathrm{H}=4 \%$ & 0 & 1.353 & 6.733 \\
\hline $\mathrm{H}=6 \%$ & 0 & 1.759 & 8.768 \\
\hline
\end{tabular}

Fig [14] Max-deflection at mid- span Deflection mid-span.
Fig [12] Max- Horizontal Displacement Vs. Degree of curvature $(S=40 \mathrm{~m})$

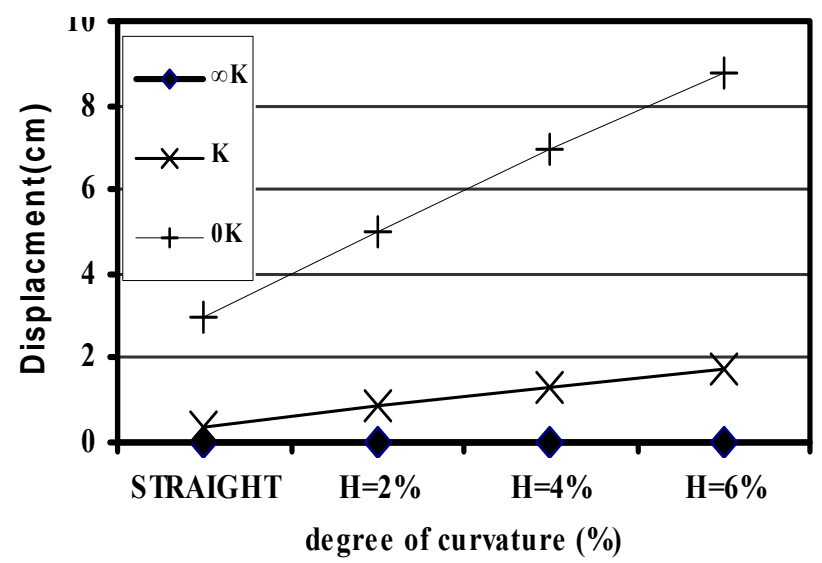

Fig [13] Max- Horizontal Displacement Vs. Degree of curvature $(S=50 \mathrm{~m})$

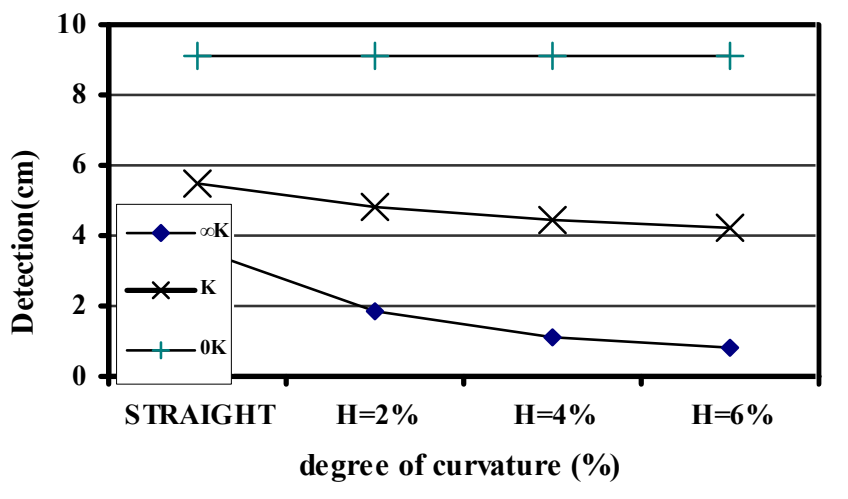

Table [18] the results of the Max-

Span Vs .Degree of curvature $(S=30 \mathrm{~m})$

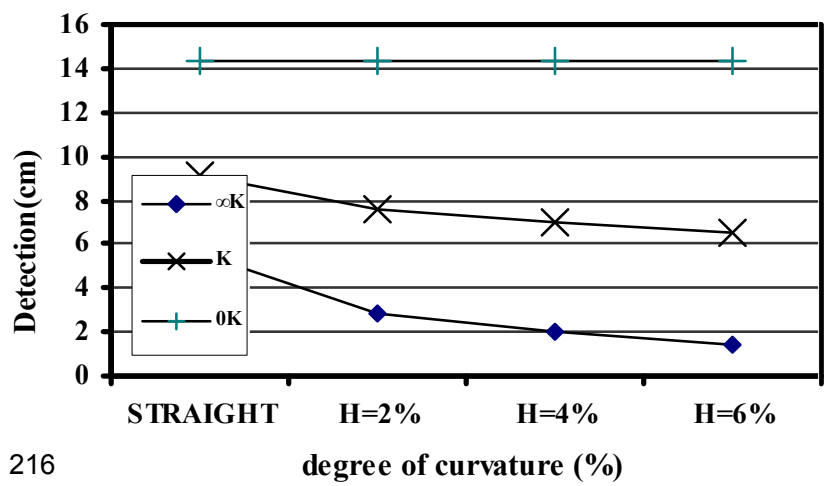


Table [19] the results of the deflection At mid-span.

Table [20] the results of the deflection at mid-span.
Fig [15] Max-deflection at mid-span Vs. Degree of curvature ( $S=40 \mathrm{~m})$

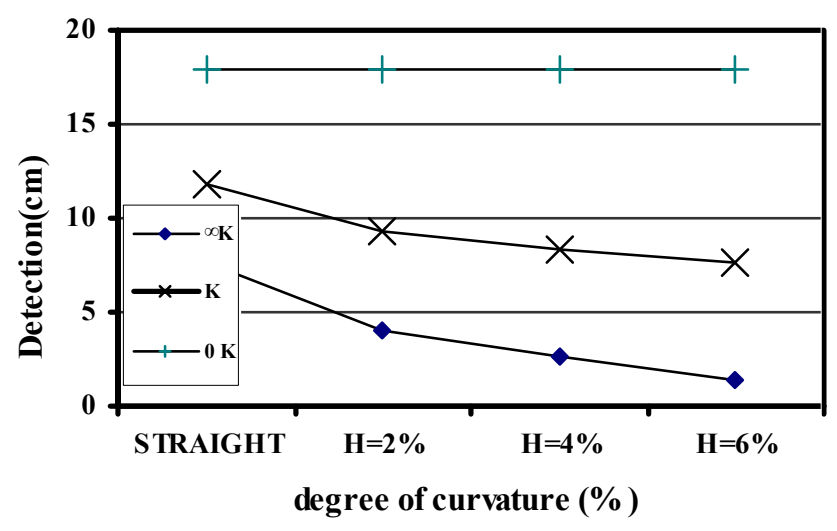

Fig [16] Max- deflection at midSpan Vs Degree of curvature $(S=50 \mathrm{~m})$

\begin{tabular}{|c|c|c|c|}
\hline TYPE & $\infty \mathrm{K}$ & $\mathrm{K}$ & $0 \mathrm{~K}$ \\
\hline STRAIGHT & 7.69 & 11.817 & 17.966 \\
\hline $\mathrm{H}=2 \%$ & 4.09 & 9.64 & 17.937 \\
\hline $\mathrm{H}=4 \%$ & 2.508 & 8.688 & 17.94 \\
\hline $\mathrm{H}=6 \%$ & 1.723 & 8.229 & 17.975 \\
\hline
\end{tabular}

\section{Conclusion:-}

1- As expected, the stresses and deformations decreased as the degree of curvature increased except for Horizontal displacement, which increased. For spring constant $(k)$, the variation percentage can be summarized as follows:

(a) Tensile stresses decreases with porcent $25 \%$ as degree of curvature increased from $0 \%$ to $6 \%$.

(b) Compressive stresses decreases with percent $29 \%$ as degree of curvature incleased from $0 \%$ to $6 \%$.

(c) Horizontal reaction decreases from $0 \%$ to $6 \%$.

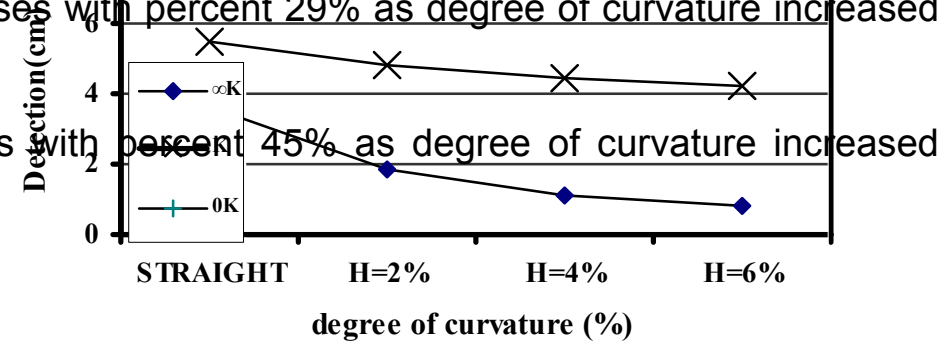


(d) Deflection decreases with percent $27 \%$ as degree of curvature increased from $0 \%$ to $6 \%$.

(e) Horizontal displacement increases with percent $153 \%$ as degree of curvature increased from $0 \%$ to $6 \%$.

2- Hinged-roller arched composite beam has no advantages relative to the straight one.

3- Hinged - Hinged supports reduce the resulting stresses and deformations. But on the other side, a significant increase in the horizontal reaction developed at the support relative to sections with less value of $(\mathrm{K})$

4- The spring constant $(K)$ as an alternative end condition has a vital effect on the resulting stresses, deformations and horizontal reactions.

5- The optimum degree of curvature obtained at $\mathrm{H}=20 \%$, which gives us minimum internal stress and deformations.

\section{REFERENCES}

[1] Deric j.Oehiers and Mark A. Bradford "Elementary Behavior of Composite Steel \& Concrete Structural Members "1999 CH.3, P44.

[2] V.Thevendran "Nonlinear analysis of steel-concrete composite beams curved in plane"

[3] J.M.Segura, G.Armengaud "Analytical formulation of stresses in curved composite beam"

[4] Wilson, E.L., and Habibullah, A., "Users Manual of SAP90," Computers \& Structures, inc., 1989.

[5] The Civil Engineering Handbook. Second Edition International Standard book 
0-8493-0958-1

[6] British standard code, "Composite Construction in Structural Steel and Concrete" Cp 117: Part 1\&2 1965 London.

[7] Zienkiewick,O.C., and Taylor,R.L.," The Finite Element Method, " Fourth Edition, McGraw-Hill, 1989. 